\title{
Are Breastfeeding Patterns in Pakistan Changing?
}

\author{
ZuBEDA KHAN
}

\begin{abstract}
Prolonged breastfeeding, apart from being beneficial to the child's health, helps in keeping the birth rate low. One of the effects of malnutrition in developing countries is the reduction in the period of lactation. In Pakistan, where the birth rate is already very high and the use of contraceptives limited, any reduction in the breastfeeding period may result in an increase of the birth rate. This study was undertaken to find out the recent changes in the breastfeeding pattem and their potential impact on the fertility levels in Pakistan. The data for this study is based on two National Fertility Surveys - the 1975 Pakistan Fertility Survey (PFS) and the 1979 Population, Labour Force, and Migration Survey (PLM). The estimation of the mean duration of breastfeeding is based on a measure developed by mosley (1982), given by the formula $\bar{Y}=B / \bar{N}$, where $\bar{Y}=$ estimate of duration of breasteeding, $B=$ total number of children currently being breastfed, $\bar{N}=$ the average number of births per month. Taking mother's age, parity, place of residence, education, and occupation as background variables, the findings are as follows: (1) a decline of aboul 4 months occurs in the average length of lactation; (2) age of mother is positively associated with the duration of breastfeeding; (3) urban women have shorter periods of breastfeeding; (4) women working on farms have longer periods of breastfeeding; (5) a slight increase in fertility is due to the decline in breastfeeding and the decrease in the use of contraceptives. It is suggested that breastfeeding may be promoted among Pakistani mothers to reduce the birth rate.
\end{abstract}

\section{INTRODUCTION}

Prolonged breastfeeding, apart from being beneficial to the health of the child, makes an important contribution to maintaining lower fertility rates. This role of breastfeeding is of profound demographic significance in developing countries such as Pakistan, where the use of contraception continues to be low. The fertility-reducing effect of breastfeeding stems from the fact that, after giving birth, a woman becomes temporarily infertile for a period, the length of which is directly related to the duration of breastfeeding [Corsini (1979); Jain, Hermalin and Sun Islamabad.

Zubeda Khan is Research Demographer at the Pakistan Institute of Development Economics,

Author's Note: I am extremely grateful to Dr Zeba A. Sathar for her guidance in preparing this paper. I am also thankful to the anonymous referee of this Journal for the valuable comments and suggestions made by him; to Mr M. Afzal for helpful comments made by him on an earlier draft of the paper, and to Mr M. Rafiq for his help with programming and obtaining statistical results. The excellent typing support of Mr Fazle Akbar is also appreciated. However, only I am responsible for any shortcomings of the paper. 
(1979)]. The length of this period (post partum amenorrhea) extends from about two months (for those women who do not breastfeed at all) to about two years (with prolonged breastfeeding). [Jellife and Jellife (1972).] ${ }^{1}$

It has been observed that with the process of modernization, some of the traditional norms which favour breastfeeding practices may be changing in many parts of the developing world. The declines in the incidence and prevalence of traditional lactational practices may be contributing to an upsurge in the fertility levels of such populations [Dyson (1988)]. In Pakistan, where the use of contraception is limited to only a small fraction of urban women, or those who are educated, any decline in breastfeeding practices would contribute further to the prevailing high levels of fertility. The objective of this paper is to investigate the recent changes in breastfeeding practices as well as their potential impact on the fertility levels in Pakistan. ${ }^{2}$

The study has used data from two national fertility surveys - the 1975 Pakistan Fertility Survey (PFS) and the 1979 Population, Labour Force, and Migration Survey (PLM). ${ }^{3}$ The major aim is to identify any changes in the mean duration of breastfeeding between the dates of those two surveys. Information on breastfeeding is extracted from reproductive histories collected for all women in the sample in the two surveys.

Both surveys are nationally representative; they utilized an identical fertility module, and are, theoretically, directly comparable. The reader, however, must be cautioned against general data problems in Pakistan, and in recall of dates and ages, in particular, which directly influence the type of results found in this paper. Reporting of the duration of breastfeeding, in particular the birth-dates of children (on which the estimates of birth intervals are based) and ages of women, are known to be particularly problematic in Pakistan. Further, though the questionnaires of the two surveys are identical, the quality of field-work may have differed. Some of the characteristics of the samples of the two surveys - such as the larger proportions of urban women and educated women in the PLM as compared to the PFS, and the unusually low proportions of single women at ages 20-24 found in the PFS as compared to the PLM and the 1981 Census - indicate the use of a significantly different sample even though both surveys are claimed to be nationally representative

${ }^{1}$ Among lactating women, ovulation and menstruation are delayed by a period of $2.5-26$ months, the upper limit being applicable to the cases wherein breastfeeding is complete and unsupplemented.

${ }^{2}$ This analysis is limited to the potential impact on the fertility levels through changes in the amenhorrea period due to the changes in lactation. However, changes in breastfeeding also act through its effect on infant mortality, which in turn may affect fertility also. These routes have not been explored in this paper.

${ }^{3}$ The total sample size was 4949 ever-married women in 1975 and 10,086 in 1979. 
(Appendix Table). Therefore, the results of the analysis should be regarded as tentative until confirmed further by a similar fertility survey, such as the Pakistan Demographic Health Survey, which is being fielded currently.

\section{METHODOLOGY AND RESULTS}

To estimate the mean duration of breastfeeding, this study has used a measure developed by Mosley et al. (1982), which requires information on the total number of children currently breastfed in the sample population (irrespective of their ages) and the total number of births that have occurred during the specified period (per month for example) in the same population. For this purpose, the number of children reported as being currently breastfed is considered a measure of prevalence of breastfeeding, which is a function of the number of children who start breastfeeding (taken as the incidence) and the duration of those still breastfeeding, with a constant stream of entrants. The estimation of mean duration is obtained by dividing the observed prevalence by the estimated incidence.

Denoting the total number of children currently breastfed by $B$, and the average number of births per month by $\bar{N}$, the estimate of mean duration of breastfeeding is as follows:

$$
\bar{Y}=B / \bar{N}
$$

This measure is relatively insensitive to errors in the reported dates of birth for the children in question, because the numerator does not require information on the dates of birth, but these can be calculated from births in the specified period preceding the survey. However, only those women who had at least one birth during the period concerned are included in the base.

In estimating the mean duration of breastfeeding from the 1975 PFS Survey and the 1979 PLM Survey, we have used the number of births occurring during the four years preceding each survey. These were available from the maternity histories of the women interviewed. The period of four years was selected to obtain an adequate number of births, as well as to restrict information to births occurring in a recent enough time-period to provide a better recall of birth events.

\section{TRENDS IN BREASTFEEDING: PREVALENCE AND DURATION}

Table 1 shows that amongst all children born during the four years preceding the survey, as well as for those still surviving (at the time of the survey), the incidence of breastfeeding is very high. Only a very slight decline of between 1 and 3 percentage points is reported between 1975 and 1979 [see Khan (1985)]. 
Table 1

Estimates of Breastfeeding for All Children Born in the Four Years Preceding the Survey, and of Surviving Children by Age of Mother at Birth

(1975 PFS and 1979 PLM), Pakistan

\begin{tabular}{|c|c|c|c|c|c|c|}
\hline \multirow[b]{2}{*}{ Age Group } & \multicolumn{2}{|c|}{$\begin{array}{c}\text { Percentage } \\
\text { Breastfed }\end{array}$} & \multicolumn{2}{|c|}{$\begin{array}{l}\text { Mean Duration } \\
\text { Breastfeeding } \\
\text { (Months) }\end{array}$} & \multicolumn{2}{|c|}{$\begin{array}{l}\text { Total Births } \\
\text { in Four Years }\end{array}$} \\
\hline & PFS & PLM & PFS & PLM & PFS & PLM \\
\hline \multicolumn{7}{|l|}{ All Children } \\
\hline All Women & 94.2 & 92.7 & 19.3 & 15.2 & 4463 & 8955 \\
\hline Women Aged $15-24$ & 92.3 & 93.0 & 17.7 & 14.7 & 1912 & 3788 \\
\hline Women Aged $25-34$ & 95.6 & 93.0 & 20.0 & 15.4 & 1930 & 3846 \\
\hline Women Aged $35-49$ & 96.0 & 91.0 & 22.2 & 16.5 & 584 & 1280 \\
\hline \multicolumn{7}{|l|}{ Surviving Children } \\
\hline All Women & 98.4 & 96.9 & 22.8 & 17.7 & 3762 & 7687 \\
\hline Women Aged $15-24$ & 97.8 & 97.2 & 21.6 & 17.0 & 1567 & 3270 \\
\hline Women Aged $25-34$ & 98.9 & 96.7 & 23.1 & 17.8 & 1666 & 3334 \\
\hline Women Aged $35-49$ & 100.0 & 97.0 & 25.8 & 20.1 & 500 & 1049 \\
\hline
\end{tabular}

Sources: Data tapes of the Pakistan Ferility Survey 1975 (PFS) and the Population, Labour Force, and Migration Survey 1979 (PLM).

The table, however, indicates that the mean duration of breastfeeding declined for mothers of all ages between the two surveys, and was particularly notable for those aged 25 years and above. If the estimates arrived at from the two surveys are accepted on their face value, then an overall decline of about 4 months in the average breastfeeding period over a period of four years is a cause of concern. This is due to possible implications for maintaining already high fertility levels, especially in view of the fact that contraceptive use levels in Pakistan are reported to be less than 10 percent. For the purpose of understanding more fully this dramatic change in breastfeeding, it is essential to study whether it has occurred across the board or only applies to selected groups of women.

In other societies, mother's age has been found to have a positive influence on the duration of breastfeeding [for example, see Jain et al. (1970) for Taiwan]. This association was also found in the earlicr survey (PFS), where the children born to young mothers (15-24 age-group) were, on average, breastfed 4-5 months less than the children born to older women (35-49 age-group). In the later survey (PLM), there is, on average, 1.8 months difference in duration of breastfeeding between the younger and older mothers. For surviving children, a more consistent 
pattern was observed across the PFS and PLM data, and a 3-4 months difference in the breastfeeding duration was found between the younger mothers (15-24 agegroup) and older mothers (35-49 age-group).

\section{BREASTFEEDING BY PARITY}

A number of factors are important in the association between parity and breastfeeding duration. For instance, lower parity women tend to be young, and the majority are from urban areas where breastfeeding periods are relatively short. A comparison in Table 2 indicates that women's parity has a consistent positive association with the percentage of children breastfed particularly in the case of the PFS. Also, it is clear from looking at later parity figures that the duration of breastfeeding increases with parity. In 1975, the mean duration of breastfeeding for the first child was 17.3 months, and at parity $7+$ it was 21.2 months. Similarly in 1979 , the mean duration of breastfeeding for the first child was 13.7 months, and at parity $7+$ it was 16.2 months. The temporal decline in the mean duration of breastfeeding is seen across parity groupings: in 1975 at parity 1 the mean duration of breastfeeding was 17.3 months, and it was as low as 13.7 in the PLM and a similar decline was observed between higher parity groupings. The curvilinear trend in the proportions of children ever breastfed, seen in the PLM, is puzzling and in contradiction with the other findings of the table.

\section{Table 2}

Estimates of Mean Duration of Breastfeeding for all Children Born in the Four Years Preceding the Survey, by Parity of Mothers

(1975 PFS and 1979 PLM), Pakistan

\begin{tabular}{|c|c|c|c|c|c|c|}
\hline & \multicolumn{2}{|c|}{$\begin{array}{c}\text { Percentage } \\
\text { Breastfed } \\
\end{array}$} & \multicolumn{2}{|c|}{$\begin{array}{c}\text { Mean Duration } \\
\text { Breastfeeding } \\
\text { (Months) }\end{array}$} & \multicolumn{2}{|c|}{$\begin{array}{l}\text { Total Births } \\
\text { in Four Years }\end{array}$} \\
\hline & PSF & PLM & PFS & $\overline{\text { PLM }}$ & PFS & PLM \\
\hline \multicolumn{7}{|c|}{ Parity } \\
\hline 1 & 90.4 & 90.7 & 17.3 & 13.7 & 714 & 1448 \\
\hline $2-3$ & 94.4 & 93.7 & 18.9 & 14.7 & 1277 & 2692 \\
\hline $4-6$ & 94.9 & 93.5 & 19.2 & 15.9 & 1456 & 2977 \\
\hline $7+$ & 95.8 & 91.3 & 21.2 & 16.2 & 1016 & 1838 \\
\hline
\end{tabular}

Sources: Data tapes of the Pakistan Fertility Survey 1975 (PFS) and the Population, Labour Force, and Migration Survey 1979 (PLM). 


\section{BREASTFEEDING BY RESIDENCE}

The change in breastfeeding patterns is usually attributed to modemization and associated preference for bottle-feeding, and is thus expected to apply more to urban children and amongst younger mothers. However, the data reveal that the decline in breastfeeding durations is slightly higher for the rural than for the urban women (Table 3). The urban-rural differential remains still high, but is somewhat narrowed. Also, when comparing percentages of mothers who ever breastfed by age groups of mothers at the time of survey, we see a decline in breastfeeding among older women between the two survey dates. In fact, durations of breastfeeding seem to have diminished most for the rural mothers of ages 25 years and above, while those rural mothers aged 15-24 years demonstrate a slighter diminution in the mean length of breastfeeding. For the urban mothers, the decline in the duration of breastfeeding is nearly of the same magnitude across all age groups. Thus, the table reveals the somewhat unexpected findings; that the older as opposed to the younger, and the rural as opposed to the urban, women are the ones whose breastfeeding behaviour seems to be changing more than that of the other corresponding groups. If this trend is extrapolated into the future, it implies a further narrowing of

\section{Table 3}

Estimates of Breastfeeding for Children Born in the Four Years Preceding the Survey, by Rural-Urban Residence of Mother, and by Age of Mother at Birth (1975 PFS and 1979 PLM), Pakistan

\begin{tabular}{|c|c|c|c|c|c|c|c|}
\hline \multirow[b]{2}{*}{ Age Group } & \multirow[b]{2}{*}{ Residence } & \multicolumn{2}{|c|}{$\begin{array}{c}\text { Percentage } \\
\text { Breastfed }\end{array}$} & \multicolumn{2}{|c|}{$\begin{array}{l}\text { Mean Duration } \\
\text { Breastfeeding } \\
\text { (Months) }\end{array}$} & \multicolumn{2}{|c|}{$\begin{array}{l}\text { Total Births } \\
\text { in Four Years }\end{array}$} \\
\hline & & PFS & PLM & PFS & PLM & PFS & PLM \\
\hline \multirow[t]{2}{*}{ All Women } & Rural & 95.0 & 93.6 & 20.4 & 16.8 & 3256 & 5472 \\
\hline & Urban & 92.2 & 91.2 & 16.1 & 12.8 & 1206 & 3483 \\
\hline \multirow{2}{*}{$\begin{array}{c}\text { Women Aged } \\
15-24\end{array}$} & Rural & 93.5 & 93.5 & 18.6 & 16.3 & 1398 & 2268 \\
\hline & Urban & 89.1 & 92.2 & 15.3 & 12.2 & 513 & 1520 \\
\hline \multirow{2}{*}{$\begin{array}{l}\text { Women Aged } \\
25-34\end{array}$} & Rural & 96.3 & 94.5 & 21.3 & 16.9 & 1384 & 2320 \\
\hline & Urban & 94.0 & 90.7 & 16.6 & 13.1 & 546 & 1526 \\
\hline \multirow{2}{*}{$\begin{array}{l}\text { Women Aged } \\
35-49\end{array}$} & Rural & 95.7 & 91.8 & 23.9 & 17.8 & 445 & 855 \\
\hline & Urban & 97.1 & 89.4 & 16.7 & 13.8 & 138 & 425 \\
\hline
\end{tabular}

Sources: Data tapes of the Pakistan Fertility Survey 1975 (PFS) and the Population, Labour Force, and Migration Survey 1979 (PLM). 
the four month differential in the mean length of breastfeeding across urban and rural Pakistani women in the near future.

\section{BREASTFEEDING BY RESIDENTIAL MOBILITY}

Table 4 shows the effect of residential mobility on the incidence and duration of breastfeeding. Women whose childhood place of residence was urban, and who were also currently living in urban areas, have the smallest percentage of children ever breastfed and also the shortest length of lactation both in 1975 and in 1979. Congruously, those women whose childhood place of residence and current residence were both rural areas have the longest period of lactation. But for women whose childhood place of residence was rural but who were currently residing in urban areas, a shorter length of breastfeeding was observed than if they had not migrated. This shows that the urban environment to which women migrate seems to have a notable impact on current breastfeeding behaviour, reflecting a

\section{Table 4}

Estimates of Mean Duration of Breastfeeding for All Children Born in the Four Years Preceding the Survey, by Residential Mobility of Mother at Birth (1975 PFS and 1979 PLM), Pakistan

\begin{tabular}{|c|c|c|c|c|c|c|}
\hline & \multicolumn{2}{|c|}{$\begin{array}{c}\text { Percentage } \\
\text { Breastfed } \\
\end{array}$} & \multicolumn{2}{|c|}{$\begin{array}{c}\text { Mean Duration } \\
\text { Breastfeeding } \\
\text { (Months) }\end{array}$} & \multicolumn{2}{|c|}{$\begin{array}{l}\text { Total Births } \\
\text { in Four Years }\end{array}$} \\
\hline & PFS & PLM & PFS & PLM & PFS & PLM \\
\hline \multicolumn{7}{|c|}{ Previous-current Residence } \\
\hline Urban-Urban & 91.2 & 90.9 & 15.3 & 12.0 & 811 & 2617 \\
\hline Rural-Rural & 95.1 & 93.5 & 20.4 & 16.9 & 3057 & 5206 \\
\hline Rural-Urban & 94.3 & 92.3 & 17.8 & 15.2 & 395 & 866 \\
\hline
\end{tabular}

Sources: Data tapes of the Pakistan Fertility Survey 1975 (PFS) and the Population, Labour Force, and Migration Survey 1979 (PLM).

lesser role of early socialization on breastfeeding behaviour. Alternatively, one could argue that the rural outmigrants were selected by characteristics which were to show once they came to the urban areas, and that it was the early selection which was operational, rather than the lack of socialization, within rural areas. 


\section{CHANGES IN BREASTFEEDING BY MOTHER'S CHARACTERISTICS}

In most settings it has been observed that the length of breastfeeding decreases monotonically with the educational level of mothers. Table 5 shows the same pattern for Pakistan, where women with some education breastfed for shorter durations than women with no schooling. However, illiterate mothers and those who had upto a primary education had almost a similar length of breastfeeding in both the PFS and the PLM. The main difference between the two surveys is in the mean length of breastfeeding of women with above-primary education, which implies a much greater educational differential in breastfeeding in the PFS as compared to the PLM. However, it should be noted that the number of observations on which the averages for women with more than middle schooling in the PFS is quite small and, therefore, the PLM results may be more reliable. A similar pattern was observed across the three age groups for these categories of education. Also, educated women were generally less likely to have ever breastfed their children than mothers with no education: 95 percent of the children of uneducated mothers were ever-breastfed as compared to the 84 percent of those with mothers with a primary education in the PFS; while the corresponding figures for the PLM were 93 percent and 87 percent, respectively.

Table 5

Estimates of Mean Duration of Breastfeeding for All Children Born in the Four Years Preceding the Survey, by Education of Mother at Birth (1975 PFS and 1979 PLM), Pakistan

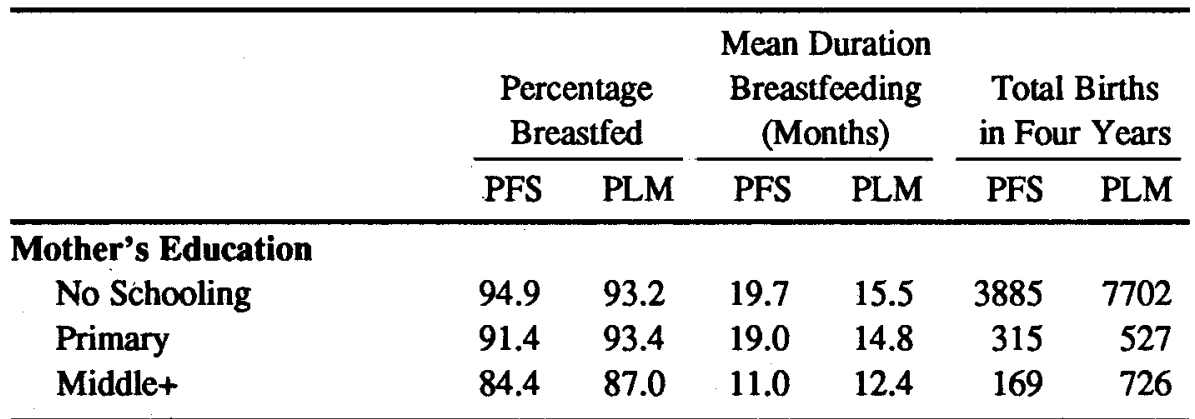

Sources: Data tapes of the Pakistan Fertility Survey 1975 (PFS) and the Population, Labour Force, and Migration Survey 1979 (PLM).

\section{BREASTFEEDING BY MOTHER'S OCCUPATION}

Due to small numbers in each occupation group, we categorized working 
women into two broad groups of those in agriculture and those in non-agricultural occupations. Table 6 shows that those in agriculture have longer breastfeeding durations than non-working women and women in non-agricultural occupations. This pattern was true for both the PFS and the PLM surveys. However, when figures for breastfeeding for non-working women by urban-rural residence are compared, the occupational differences become negligible.

Table 6

Estimates of Mean Duration of Breastfeeding for All Children Born in the Four Years Preceding the Survey, by Mother's Occupation (1975 PFS and 1979 PLM), Pakistan

\begin{tabular}{|c|c|c|c|c|c|c|}
\hline & \multicolumn{2}{|c|}{$\begin{array}{c}\text { Percentage } \\
\text { Breastfed }\end{array}$} & \multicolumn{2}{|c|}{$\begin{array}{c}\text { Mean Duration } \\
\text { Breastfeeding } \\
\text { (Months) }\end{array}$} & \multicolumn{2}{|c|}{$\begin{array}{l}\text { Total Births } \\
\text { in Four Years }\end{array}$} \\
\hline & PFS & PLM & PFS & PLM & PFS & PLM \\
\hline \multicolumn{7}{|c|}{ Mother's Occupation } \\
\hline Not Working & 94.1 & 92.7 & 19.6 & 15.2 & 3657 & 7987 \\
\hline $\begin{array}{l}\text { Urban } \\
\text { Rural }\end{array}$ & $\begin{array}{l}91.8 \\
95.0\end{array}$ & $\begin{array}{l}91.5 \\
93.5\end{array}$ & $\begin{array}{l}16.5 \\
20.8\end{array}$ & $\begin{array}{l}13.0 \\
16.8\end{array}$ & $\begin{array}{l}1004 \\
2653\end{array}$ & $\begin{array}{l}3247 \\
4740\end{array}$ \\
\hline Agriculture & 97.6 & 94.3 & 20.1 & 16.8 & 232 & 543 \\
\hline Non-agriculture & 93.5 & 90.6 & 16.7 & 13.4 & 573 & 425 \\
\hline
\end{tabular}

Sources: Data tapes of the Pakistan Fertility Survey 1975 (PFS) and the Population, Labour Force, and Migration Survey 1979 (PLM).

\section{BREASTFEEDING AND FERTILITY}

Since a decline in reported lactation has been identified in the period 1975-1979, and because breastfeeding is a powerful variable in explaining fertility levels, especially in traditional societies where the use of contraception is low, we need to assess the impact of this decline on fertility. For this purpose, we applied the Bongaarts model to assess the contribution of the four major intermediate fertility variables on fertility; such as (1) proportions married among females; (2) contraceptive use effectiveness; (3) duration of post-partum infecundability; and (4) prevalence of induced abortions. Three other variables, according to Bongaarts, appear to be less important at the aggregate level, i.e., fecundability, spontaneous intra-uterine mortality rate, and prevalence of permanent sterility. Thus, the first four variables are emphasized in the Bongaarts framework. Among them are the 
requisite data on induced abortion, which are close to impossible to collect in an Islamic State like Pakistan, where religious and social pressures are a great hinderance to obtaining such information.

Formulas for estimating the indexes of the intermediate fertility variables from the basic input data are summarized in the following format.

The Model requires data for the following variables: ${ }^{4}$

$C_{m}=T F R / T M$

therefore

$$
\begin{aligned}
C_{m}(1975) & =7.0^{1} / 8.18^{1} \\
& =.855
\end{aligned}
$$

and

$$
\begin{aligned}
C_{m}(1979) & =6.5^{2} / 8.1^{2} \\
& =.802
\end{aligned}
$$$$
C_{c}=1-1.18 u . e
$$

therefore

$C_{c}(1975)$

$$
\begin{aligned}
& =1-(1.18)(0.052)^{3}(0.83)^{1} \\
& =1-0.051 \\
& =0.949
\end{aligned}
$$

and

$C_{c}(1979)$

$=1-(1.18)(0.033)^{3}(0.83)^{4}$

$=1-0.032$

$=0.968$

$C_{i}=20 / 18.5+i$,

where, $i=1.5+0.56 L^{5}$

therefore

$C_{i}$ (1975)

$$
\begin{aligned}
& =20 /[18.5+[1.5+(0.56)(19.3)]] \\
& =20 /[18.5+(1.5+10.8)] \\
& =20 /[18.5+12.3] \\
& =20 / 30.8 \\
& =0.65
\end{aligned}
$$

and

$C_{i}$ (1979)

$$
\begin{aligned}
& =20 /[18.5+(1.5+8.5)] \\
& =20 /[18.5+10.0] \\
& =20 / 28.5 \\
& =0.70
\end{aligned}
$$$$
=20 /[18.5+[1.5+(0.56)(15.2)]]
$$

41. [Sathar (1984) Table 7.1.]

2. [Alam et al. (1983) Tables 12 and 13.]

3. [Soomro and Ali (1983) Table 5.]

4. $e$ is assumed to be 0.83 as was the case in 1975 .

5. $L$ was equal to 19.3 months in PFS, and to 15.2 months in PLM. (Table 1 page 6). 
As can be seen quite clearly, the values for both surveys do fall into the acceptable range (Table 7). Subsequently, we proceed to apply the Bongaarts model primarily to assess the likely relative impact of changes in breastfeeding on fertility across the two surveys.

\section{Table 7}

Summary of Estimation of Indexes of Intermediate Fertility Variables, Fertility Measures, and Required Input Measures for Bongaarts Model

\begin{tabular}{ccc}
\hline & Approximate Observed Range: & \\
& Countries with High Fertility & Method of \\
Variable & (TFR Greater than 5) & Estimation \\
\hline
\end{tabular}

\section{Indexes of Intermediate}

Fertility Variables

$C_{m}=$ Index of Proportion Married

$0.65-0.9$

$C_{m}=T F R / T M$

$C_{c}=$ Index of Non-contraception

Variable

$0.8-1.0$

$C_{c}=1-1.18$ u.e

$C_{i}=$ Index of Lactational

Infecundability

$0.5-0.7$

$C_{i}=20 / 18.5+i^{*}$

\section{Fertility Measures}

$T F R=$ Total Fertility Rate

$T M=$ Total Marital Fertility Rate

As Observed

\section{Required Input Measures}
$U=$ Average Proportion of Married Women Currently Using Contracep- tion
$e=$ Average Effectivness of Contracep- tion
$0-0.2$
As Observed
$i=$ Average Duration of Lactational Infecundability (Months)
n.a.
$10-20$
As Observed
As Observed

Sources: [Bongaans (1978) Table 2.]

* $i$ can be estimated from the mean duration (in months) of lactation; $L$, with the following equation: $i=1.5+0.56 \mathrm{~L}$. (The mean duration of lactation is easily calculated by duration since the last birth is known.) 
The application of the model demonstrates (in Table 8) that the slight increase in total marital fertility in Pakistan has probably been contributed largely by the decline in breastfeeding, and, to a lesser extent, by the decline in contraceptive use. While estimating the Bongaarts indices, we find that the combined measure $\left(C_{m} \times C_{c} \times C_{i}\right)$ presents a figure conflicting with the actual trend in fertility. It implies that the TFR should have risen by 3 percent, whereas a slight decline is noted in the TFR between 1975 and 1979 . This is most likely due to the fact that contraceptive use was under-reported in the PLM [Soomro et al. (1983)]; however, the total fertility rate of 6.5 found in the PLM could in itself be subject to underreporting of births.

Table 8

Application of the Bongaarts Framework to PFS 1975 and PLM 1979, Pakistan

1975

1979

$1979 / 1975$

Measures

Total Fertility Rate (TFR)

7.0

6.5

0.928

Total Marital Fertility Rate (TM)

8.18

8.1

0.990

Current Contraceptive Use $(U)$

0.052

0.033

0.634

Contraceptive Effectiveness (e)

0.83

0.83

1.000

Lactational Infecundability (i)

12.3

10.0

0.813

\section{Index}

Index of Proportions Married $\left(C_{m}\right)$

0.855

0.802

0.938

Index of Non-contraception $\left(C_{c}\right)$

0.949

0.968

1.020

Index of Lactational

Infecundability $\left(C_{i}\right)$

0.65

0.70

1.077

Combined Indexes $\left(C_{m} \times C_{c} \times C_{i}\right)$

0.527

0.543

1.030

Sources: 1. [Sathar (1984) Table 7.1.]

2. [Alam et al. (1983) Tables 12 and 13.]

3. [Socmro and Ali (1983) Table 5.]

4. $e$ is assumed to be 0.83 as was the case in $\mathbf{1 9 7 5}$.

5. $L$ was equal to 19.3 months in PFS, and to 15.2 months in PLM. (Table 1 page 6.)

\section{SUMMARY AND CONCLUSIONS}

This analysis of breastfeeding was based on data from the PFS and the PLM surveys. Since we were interested in estimating the mean duration of breastfeeding, data of all the births occurring during the four-year period prior to each survey have been used to apply Mosely's Method to estimate the mean length of lactation. 
In this analysis mother's age, parity, place of residence, education, and occupation have been selected as background variables.

The salient findings are as follows:

1. There is a decline of about 4 months in the average length of breastfeeding in the four-year period between the two surveys;

2. Age of the mother is positively associated with the duration of breastfeeding;

3. Parity has an important effect on the length of lactation; particularly the first child is breastfed for shorter periods than subsequent children;

4. Place of residence continues to influence the differentials in breastfeeding with women living in the urban areas; the breastfeed for shorter periods than women living in the rural areas;

5. The urban environment to which women migrate seems to have a notable impact on current breastfeeding behaviour, reflecting a lesser role of early socialization - or a selection effect which differentiates those families which do decide to migrate - on breastfeeding behaviour; and

6. Women's education plays a very important role in shortening the length of breastfeeding. But at the same time, there is also a recent trend towards prolonged breastfeeding among young educated mothers.

\section{POLICY IMPLICATIONS}

The decline in the duration of breastfeeding, if all else remains the same, tends to decrease the intervals between births and will, therefore, increase fertility unless compensated by a simultaneous increase in the use of contraception. The data from 1975 and 1979 show that although the length of breastfeeding has declined, it has not been accompanied by a rise in contraceptive use. This has serious implications for the already high fertility rate being experienced in Pakistan. Just to counter the present decline in length of lactation, contraceptive use rates would have to rise to $8.3^{5}$ percent (from the 3.3 percent recorded in 1979) in order to retain stable fertility levels.

Further, the decline observed in the duration of breastfeeding in the PLM survey may also have a positive effect on the child mortality levels, unless offset by other means of family limitation, because of the widely established negative link between birth spacing and infant child mortality. Thus, population planners have to consider the declining breastfeeding trend in formulating targets, and will have to

${ }^{5}$ Computed by using the Bongaarts formula, assuming that all other indices except $C_{i}$ were to remain the same for 1979 . 
work with doctors, nutritionists, health workers, and the media to promote breastfeeding among Pakistani mothers. The purpose of such a policy will be dual; firstly, to improve children's health, and then to arrest the decline in breastfeeding which may cause fertility levels to rise further.

\section{Appendix Table}

Appendix

Percentage Distribution of Some Background Characteristics in the PFS and PLM Samples

\begin{tabular}{lrr}
\hline Characteristics & PFS & PLM \\
\hline Rural-Rural & 68 & 58 \\
Urban-Rural & 4 & 3 \\
Rural-Urban & 9 & 10 \\
Urban-Urban & 18 & 29 \\
Educational Level & & \\
$\quad$ Illiterate & 87 & 86 \\
Primary & 7 & 6 \\
Middle+ & 4 & 8 \\
Not Reported & 2 & - \\
Proportions Married, By Age & & \\
15-19 & 38 & 28 \\
20-24 & 77 & 75 \\
25-29 & 89 & 92 \\
\hline
\end{tabular}

Sources: 1. Data tapes of the Pakistan Fertility Survey 1975 (PFS) and the Population, Labour Force, and Migration Survey 1979 (PLM).

2. [Sathar et al. (1984).]

\section{REFERENCES}

Alam et al. (1983) Fertility Levels, Trends and Differentials in Pakistan: Evidence from the Population, Labour Force and Migration Survey 1979-80. Islamabad: Pakistan Institute of Development Economics. (Population, Labour Force and Migration Project Reports No. 1.)

Bongaarts, J. (1978) A Framework for Analyzing the Proximate Determinants of Fertility. Population and Development Review $4: 1$ 105-132.

Corsini, Carlo A. (1979) Is the Fertility-reducing Effect of Lactation Really Substantial? Chapter 9 (pp. 195-215). In Henri Leridon and Jane Menken (eds) Natural Fertility. Liege: Ordina Editions. (Published for the International Union 
for the Scientific Study of Population.)

Dyson. T. (1988) Decline of Traditional Fertility Restraints. IPPF. Medical Bulletin $22: 6$.

Jain, A., K. T. C. Hsu., R. Freedman and M. C. Chang (1970) Demographic Aspect of Lactation and Post-Partum Amenorrhoea. Demography 7 : 255-271. Jain, Anrudh K., Albert I. Hermalin, and T. H. Sun (1979) Lactation and Natural Fertility. Chapter 8 (pp. 149-194). In Henri Leridon and Jane Menken (eds) Natural Fertility. Liege: Ordina Editions. (Published for the International Union for the Scientific Study of Population.)

Jellife, D. B., and Patrice E. F. Jellife (1972) Lactation, Conception, and Nutrition of the Nursing Mother and Child. Tropical Pediatrics 81 : 4 45-9.

Khan, Z. (1985) Breastfeeding in Pakistan. Islamabad: Pakistan Institute of Development Economics. (Population, Labour Force and Migration Project Reports No. 10.).

Mosley, W. H., L. H. Werner and S. Becker (1982) The Dynamics of Birth Spacing and Marital Fertility in Kenya. Voorburg: International Statistical Institute. (WFS Scientific Report No. 30.)

Sathar, Z. A. (1984) Intervening Variables in Fertility in Pakistan: A Review of Findings from the Pakistan Fertility Survey: 113-122. Voorburg. The Netherlands: International Statistical Institute.

Sathar, Z. A., S. Mubashir Ali and G. M. Zahid (1984) Socio-economic and Demographic Characteristics of the Population in Pakistan: Findings of the Population, Labour Force and Migration Survey 1979-1980. Islamabad: Pakistan Institute of Development Economics. (Population, Labour Force and Migration Project Reports No. 8.)

Soomro, G. Y., and S. M. Ali (1983) Prevalence of Knowledge and Use of Contraception in Pakistan. Islamabad: Pakistan Institute of Development Economics. (Population, Labour Force and Migration Project Reports No. 3.) 